\title{
Interactive Programme on Prevention of Smoking: Pilot study
}

\author{
Roswati Nordin*, Zamzaliza Abd Mulud, \\ Norimah Said, Norfidah Mohamad \\ ${ }^{1}$ Nursing Department, Faculty of Health Sciences, \\ Universiti Teknologi MARA, Puncak Alam, 42300, Selangor. \\ roswati2808@puncakalam.uitm.edu.my
}

\begin{abstract}
In order to make Malaysia a developed nation by 2020 one of the crucial things is health care and to conduct prevention at an early stage. Hence, health education programme at an early stage has been conducted with primary school children to prevent them from engaging in negative behaviours such as smoking. Currently, the health education programme was organized in poster presentation form. However, in these studies, it was transformed into an interactive school health programme with an active participation from the school children. It is designed to increase the children's learning retention through an active interaction programme.
\end{abstract}

Keywords: Interactive Programme; School Children; Smoking Prevention; Health Education

eISSN 2398-4279 @ 2018. The Authors. Published for AMER ABRA cE-Bs by e-International Publishing House, Ltd., UK. This is an open access article under the CC BY-NC-ND license (http://creativecommons.org/licenses/bync-nd/4.0/). Peer-review under responsibility of AMER (Association of Malaysian Environment-Behaviour Researchers), ABRA (Association of Behavioural Researchers on Asians) and cE-Bs (Centre for EnvironmentBehaviour Studies), Faculty of Architecture, Planning \& Surveying, Universiti Teknologi MARA, Malaysia.

DOI: https://doi.org/10.21834/ajqol.v3i12.146 


\subsection{Introduction}

Decades ago, the school atmosphere has been a focal point of hard work to influence adolescents on the consequences of smoking behaviour and other negative behaviours such as alcohol consumption and misuse of drugs (Woolfall et al., 2008). In 2003, a survey conducted by the Malaysian Global Youth Tobacco Survey (GYTS) identified that one in three students have smoked cigarettes, $25.3 \%$ of the students have used other tobacco products, $19.9 \%$ presently smoke cigarettes and $7.9 \%$ presently use other tobacco products (Manimaran, 2003).

An achievable outcome is through the enhancement of the children's physical and mental abilities. However, with multiple negative factors lurking within the social environment, this achievement could be jeopardised. Tobacco smoking, alcohol and illicit drug consumptions, poor maintenance of physical, mental and general health among others can be major inhibitors. Thus, to prevent health problems and in order to produce the next healthy generation who are able to serve the society and nation, the logical strategy is to tackle the issue among children from the primary school level (Asia et al., 2007).

Evidence supports the effectiveness of some school-based interventions tackling smoking misuse, dietary risks and sedentary behaviour (Gorini et al., 2014). To improve on this, an interactive school health prevention programme is being developed. It is designed to increase the children's learning retention through an active interaction programme. The aim of this programme is to increase awareness and knowledge regarding tobacco use and the side effects of smoking from an early age. The content in the programme enables school children to be critical viewers and critical thinkers towards tobacco use and the importance in prevention at an early age.

\section{Literature Review}

The study by WHO found that uses of harmful and hazardous licit substances such as tobacco are responsible for a myriad of risk factors causing social, financial, legal, and relationship problems for the individual and their families and eventually the communities at large. It has been proven that licit substances such as tobacco is among the top 20 factors causing ill-health worldwide (WHO, 2011). In two decades, teenagers become more exposed to tobacco advertising at an early age and most of the smokers reported that they began smoking before the age of ten (WHO, 2011).

Smoking behaviour has been and will be a problematic behaviour that demoralises academic success. This correlates with poor school commitment, risky sexual behaviour, and subsequent behavioural and emotional disorders in adulthood (Hiemstra et al., 2014). It is predicted that by the end of the 21 st century, tobacco will have killed one billion people (WHO, 2008). The earlier the children begin to smoke, the harder the possibility to quit the habit (Storret al., 2004). Normally, it is very hard for a person to stop smoking once he has become a habitual smoker. Another study has shown that the earlier the youngsters, chances are that largely they will be addicted to nicotine and become smokers upon reaching adulthood (Office of Adolescent Health, U.S. of Health \& Human Services, 2013).

Broad scopes of factors have been identified to have an influence on younger children's 
smoking and these also include negative behaviours such as substance abuse (O'Loughlin et al., 2009). Other studies showed several threat factors have been identified in the prophecy of adolescent smoking behaviours. These factors include age, male gender, parental smoking, smoking friends, socioeconomic status, family problems, and the perception that smoking is harmful to health and tobacco advertisements (Gaffar et al., 2013).

Smoking among children in early ages is well documented as a common cause of smoking because the dependency on smoking can occur between $60-90 \%$ of people who have smoked more than a few cigarettes. The earlier people start to smoke, the higher their potential of becoming a habitual smoker as well as being increasingly difficult to stop smoking (Guo, Lee, Liao, \& Huang, 2015). Most of these programmes are delivered in the school setting. However, the effectiveness of the programmes in the schools have had mixed results (Malmberg et al., 2014).

\subsection{Methodology}

\subsection{Participants}

A quasi-experimental design with an intervention programme was used in the study. In this study, two groups are needed in which one group of participants have an intervention programme in the school selected while the other group acts as a control group at the school selected. The purposive sampling is used in this study with selected criteria randomly used to identify the correct sample. Due to the suitability of the content of the intervention package, only level 2 of the school children were selected to participate in the study. A similar procedure was used to get samples from the control group.

\subsection{Instrument}

The questionnaire used in this study is adapted from the global school-based student health survey (GSHS) (WHO, 2013). Each individual item of the questionnaire contributes to one group score and response for each item. The total marks were then converted into a percentage in order to be fed into the knowledge scoring scale adopted from a previous studied by Swe \& Bhardwaj (2012). The students' marks were translated into a knowledge score before being grouped into three levels consisting of poor knowledge level, fair knowledge level and good knowledge level. Poor knowledge level was decided as a score of less than $33.3 \%$ of the individual total scores. Fair knowledge level was determined as scores of $33.3 \%$ or higher but less than $66.6 \%$ of the individual total scores. Good knowledge level was decided as score more than or equal to $66.6 \%$ of the individual total scores.

\subsection{Intervention Package}

The Interactive School Health Programme on Prevention of Smoking (IPoPS) was developed based on previous literature, adapted and adopted from the tobacco prevention in children (ToPIC) by Smith et al., (2008) and with a small modification to accommodate the Malaysian culture. Based on the literature reviewed, this is the first interactive programme package that 
educated school children on the prevention of smoking with an interactive and fun learning process in Malaysia. This interactive programme package allowed school children to learn new concepts of learning and is suitable for the Malaysian culture. This IPoPS programme will be given to the school children with sessions on licit and illicit substance abuse and healthcare programmes. The initial length of the IPoPS intervention programme is nine (9) hours within 3 days.

The aim of the IPoPS programme is to increase awareness and knowledge regarding tobacco use and the ill effects of smoking as well as all the side effects of smoking from an early age. The content in the IPoPS programme enables school children to be critical viewers and critical thinkers towards tobacco use and the importance of prevention at an early age. The IPoPS programme was created by a qualified lecturer who had experience in Community School Health. The programme was also disseminated to other groups of lecturers at the Nursing Department of UiTM. To make the programme a reality, the groups of lecturers conducted an intensive training session for degree students of UiTM one month before the actual IPoPS programme. The students were briefed on the content of the IPoPS programme, method of conducting and the materials to be used.

3.5 Statistical Analysis

Data was analysed using IBM Statistical Package (SPSS) Version 21. Descriptive frequency analysis was used to study the effects of the interactive school health children (IPoPS) in the intervention group. In this analysis, the total marks were converted into a percentage in order to be fed into the knowledge scoring scale adopted from a previous study by Swe \& Bhardwaj, (2012).

\subsection{Results and Discussion}

\subsection{General Knowledge on Cigarette, knowledge on dangers of smoking and knowledge on bans of smoking}

Table 1 shows the comparison of the percentage levels of general knowledge between the intervention and control groups pre- and post-intervention programme. For the intervention group, the level of knowledge increased from poor knowledge to fair and good knowledge after the intervention. However, the control group's level of knowledge for poor knowledge increased after the 2 weeks' follow up and also saw a decrease in the amount of respondents with fair knowledge but saw an increase of respondents with good knowledge after the 2 weeks' follow up. The results proved that the interactive programme had an influence in increasing level of general knowledge on cigarettes among school children.

Table 2 for both intervention and control group, the average level of knowledge on dangers of smoking increased from fair knowledge to good knowledge after the intervention. However, the intervention group's level of knowledge percentage was lower compared to the control group. This result shows that the intervention programme was effective for the intervention group. Although control group did not receive any intervention package, the result shows that the level of knowledge among students increased after the 2 weeks' follow up. The table showed that the intervention programme had a good effect in increasing the 
level of knowledge on the dangers of smoking among school children. For the control group, the intervention package may have increased their general level of knowledge on the dangers of smoking had it been given to them.

Table 3 also shows the comparison of the percentage level of knowledge for ban of smoking between the intervention and control groups pre- and post-intervention programme. For both intervention and control groups, the level of knowledge increased from a fair level of knowledge to good after the intervention. An interactive programme was effective for the intervention group despite the intervention group's level of knowledge percentage was lower compared to the control group. The table showed that the interactive programme had a good effect in increasing the level of knowledge on the ban of smoking among school children. For the control group, the intervention package may have increased their general level of knowledge on the ban of smoking had it been given to them.

Table 1: Comparison on Score of General Knowledge on Cigarette at Pre Intervention and Post Intervention

LEVEL OF KNOWLEDGE (\%)

\begin{tabular}{|c|c|c|c|c|c|c|}
\hline GROUP & & $\mathrm{N}$ & $\begin{array}{l}\text { Poor } \\
<33.3 \%\end{array}$ & $\begin{array}{c}\text { Fair } \\
33.3 \% \leq 66.6 \%\end{array}$ & $\begin{array}{l}\text { Good } \\
\geq 66.6 \%\end{array}$ & TOTAL \\
\hline \multirow[t]{2}{*}{ Intervention } & Pre & 60 & $9(15 \%)$ & 47 (78.3\%) & $4(6.7 \%)$ & $60(100 \%)$ \\
\hline & Post & 60 & $2(3.3 \%)$ & $48(80 \%)$ & $10(16.7 \%)$ & $60(100 \%)$ \\
\hline \multirow[t]{2}{*}{ Control } & Pre & 60 & $3(5.0 \%)$ & $38(63.3 \%)$ & $19(31.7)$ & $60(100 \%)$ \\
\hline & Post & 60 & $7(11.7 \%)$ & $31(51.7 \%)$ & $22(36.7 \%)$ & $60(100 \%)$ \\
\hline
\end{tabular}

Table 2: Comparison on Score of the Knowledge on Dangers of Smoking at Pre Intervention and Post Intervention

\begin{tabular}{|c|c|c|c|c|c|c|}
\hline \multicolumn{7}{|c|}{ LEVEL OF KNOWLEDGE (\%) } \\
\hline GROUP & & $\mathrm{N}$ & $\begin{array}{l}\text { Poor } \\
<33.3 \%\end{array}$ & $\begin{array}{c}\quad \text { Fair } \\
33.3 \% \leq 66.6 \%\end{array}$ & $\begin{array}{l}\text { Good } \\
\geq 66.6 \%\end{array}$ & TOTAL \\
\hline \multirow{2}{*}{ Intervention } & Pre & 60 & 0 & $36(60.0 \%)$ & $24(40.0 \%)$ & $60(100 \%)$ \\
\hline & Post & 60 & 0 & 34 (56.7\%) & $26(43.3 \%)$ & $60(100 \%)$ \\
\hline \multirow{2}{*}{ Control } & Pre & 60 & 0 & $46(76.7 \%)$ & $14(23.3 \%))$ & $60(100 \%)$ \\
\hline & Post & 60 & 0 & $31(51.7 \%)$ & $29(48.3 \%)$ & $60(100 \%)$ \\
\hline
\end{tabular}


Table 3: Comparison on Score of the Knowledge on Ban of Smoking at Pre Intervention and Post Intervention

\begin{tabular}{|c|c|c|c|c|c|c|}
\hline \multirow[b]{2}{*}{ GROUP } & \multicolumn{5}{|c|}{ LEVEL OF KNOWLEDGE (\%) } & \multirow[b]{2}{*}{ TOTAL } \\
\hline & & $\mathrm{N}$ & $\begin{array}{l}\text { Poor } \\
<33.3 \%\end{array}$ & $\begin{array}{l}\text { Fair } \\
33.3 \% \leq \\
66.6 \%\end{array}$ & $\begin{array}{l}\text { Good } \\
\geq 66.6 \%\end{array}$ & \\
\hline & Pre & 60 & 0 & $4(6.7 \%)$ & $56(93.3 \%)$ & $60(100 \%)$ \\
\hline \multicolumn{7}{|c|}{ Intervention } \\
\hline & Post & 60 & 0 & $3(5.0 \%)$ & $57(95.0 \%)$ & $60(100 \%)$ \\
\hline & Pre & 60 & 0 & $11(18.3 \%)$ & $49(81.7 \%)$ & $60(100 \%)$ \\
\hline
\end{tabular}

Control

\begin{tabular}{|c|c|c|c|c|}
\hline Post & 60 & 0 & $9(15.0 \%)$ & $51(85.0 \%)$ \\
\hline
\end{tabular}

\subsection{Effect of an Interactive Programme towards the General Knowledge on Cigarette, knowledge on dangers of smoking and knowledge on bans of smoking}

The primary goal of the study was to identify the effectiveness of an interactive programme on the prevention of smoking (IPOPS) among school children. Results showed that the intervention was effective towards increasing the school children's general knowledge on cigarette, knowledge on the dangers of smoking and knowledge on the ban of smoking.

Teaching IPoPS established positive outcomes, proving that IPoPS was effective in teaching school children the importance of smoking prevention through a short, interactive, cheerful, and fun program. The results demonstrated an increase of general knowledge on cigarette, knowledge on the dangers of smoking and knowledge on the ban of smoking after the intervention programme. The findings of this study is consistent with a study done by Smith et al. (2008) in the United States of America which found significant changes of knowledge after the introduction of an interactive programme.

The findings reported by Prokhorov et al. (2010) found that there is a significant change in knowledge that prevented children from smoking from an early age. The results were also consistent with a study conducted by Cremers et al. (2012) which discovered a significant change in knowledge on smoking for the children involved in the study. The IPoPS intervention had a positive effect on changing students' general knowledge on cigarette, knowledge on the dangers of smoking and knowledge on the ban of smoking among participants after the two weeks' follow-up. An interesting finding was an increase in general knowledge among the students who did not receive the IPoPS programme. If the IPoPS programme was introduced to the control group, the results would be much better than the current results. 


\subsection{Conclusion}

This study shows that the interactive programme on the prevention of smoking (IPoPS) among school children could improve the knowledge regarding tobacco, the dangers of smoking and the ban of smoking. Furthermore, the IPoPS programme has a fun and interactive approach which interests school children, getting them to give more attention to learn and understand the dangerous effects of smoking and tobacco use. The IPoPS programme enables children to build up the skill of decision making from a young age. This IPoPS programme could be implemented in Malaysia as part of a health programme in the school setting

\section{Acknowledgement}

The author wishes to thanks the Grant Lestari 600-IRMI/MyRA 5/3 (0023/2016) Lestari funding by Universiti Teknologi MARA (UiTM), Ministry of Education, Department of Health Promotion, Ministry of Health, and Faculty of Health Sciences UiTM, Dr Rasidah M, Dr Rashidah $\mathrm{R}$ and all students who participated in this study.

\section{References}

Asia, S., Control, T., Muhamed, S., Syed, A. Bin, Foundation, T. R., Health, T., \& Foundation, P. (n.d.). Health Care Costs of Smoking in Malaysia.

Cremers, H.-P., Mercken, L., Oenema, A., \& de Vries, H. (2012). A web-based computer-tailored smoking prevention programme for primary school children: Intervention design and study protocol. BMC Public Health, 12, 277. doi:10.1186/1471-2458-12-277

Guo, J.-L., Lee, T.-C., Liao, J.-Y., \& Huang, C.-M. (2015). Prevention of Illicit Drug Use Through a School-Based Program: Results of a Longitudinal, Cluster-Randomized Controlled Trial. Journal of Adolescent Health, 56(3), 314322. doi:10.1016/j.jadohealth.2014.12.003

Gaffar A, Alsanosy R, Mahfouz M. Sociodemographic factors associated with tobacco smoking among Intermediate and Secondary School Students in Jazan Region of Saudi Arabia. Substance Abuse. 2013; 34(4):381-8.

Gorini, G., Carreras, G., Bosi, S., et al., 2014. Effectiveness of a school based multicomponent smoking prevention intervention: The LdP cluster randomized controlledtrial. Prev. Med. (Baltim.) 61, 6-13.

Hiemstra, M., Ringlever, L., Otten, R., van Schayck, O. C. P., Jackson, C., \& Engels, R. C. M. E. (2014). Long-term effects of a home-based smoking prevention program on smoking initiation: A cluster randomized controlled trial. Preventive Medicine, 60, 65-70. doi:10.1016/j.ypmed.2013.12.012

Lee, M. Y., \& Tam, C. L. (n.d.). Smoking and Burden of III Health : A Review of the Malaysian Context, 6(7), 190198.

Malmberg, M., Kleinjan, M., Overbeek, G., Vermulst, A., Monshouwer, K., Lammers, J., ... Engels, R. C. M. E. (2014). Effectiveness of the "Healthy School and Drugs" prevention programme on adolescents' substance use: A randomized clustered trial. Addiction, 109, 1031-1040. doi:10.1111/add.12526

Mathers, C. D., \& Loncar, D. (2005). Updated projections of global mortalityand burden of disease, 2002-2030:data 
sources, methods and results. .

Norbanee, T. H., Norhayati, M. N., Norsa'adah, B., \& Naing, N. N. (2006). Prevalence and factors influencing smoking amongst Malay primary school children in Tumpat, Kelantan. Southeast Asian Journal of Tropical Medicine and Public Health, 37(1), 230-235.

Prokhorov, A. V, Kelder, S. H., Shegog, R., Conroy, J. L., Murray, N., Peters, R., ... Ford, K. H. (2010). Project ASPIRE: an Interactive, Multimedia Smoking Prevention and Cessation curriculum for culturally diverse high school students. Substance Use \& Misuse, 45, 983-1006. doi:10.3109/10826080903038050

Smith, T. M., Talley, B., Hubbard, M., \& Winn, C. (2008). Evaluation of a tobacco prevention program for children: ToPIC. Journal of Community Health Nursing, 25, 218-28. doi:10.1080/07370010802421210

Swe, K. M. M., \& Bhardwaj, A. (2012). Knowledge and Practice of First Year Medical Students about Smoking. International Journal of Collaborative Research on Internal Medicine \& Public Health (IJCRIMPH), 4(5), 785-795.

Woolfall, K., Porcellato, L., Stredder, K., Wareing, M., Atkinson, A., Lushey, C., ... Sumnall, H. (2008). Preventing the uptake of smoking by children - Focus Group Report, 1-94.

World Health Organization. WHO Report on the Global Tobacco Epidemic, (2011). Geneva: WHO

World Health Organization. global school-based student health survey , (2013). Geneva: WHO

World Health Organization. (2014). World Health statistics 2013. ZhurnalEksperimental'noiiTeoreticheskoiFiziki. Retrieved from http://scholar.google.com/scholar?hl=en\&btnG=Search\&q=intitle:No+Title\#0 